\title{
Ovarian Tumor Antigen-activated Autologous Dendritic Cell Vaccine
}

National Cancer Institute

\section{Source}

National Cancer Institute. Ovarian Tumor Antigen-activated Autologous Dendritic Cell

Vaccine. NCI Thesaurus. Code C115105.

A dendritic cell (DC)-based cancer vaccine composed of autologous dendritic cells (DCs) activated with an ovarian tumor cell lysate containing tumor-associated antigens (TAAs) with potential immunostimulatory and antineoplastic activities. Upon administration, the ovarian tumor antigen-activated autologous DC vaccine may stimulate an anti-tumoral cytotoxic $\mathrm{T}$-lymphocyte $(\mathrm{CTL})$ response against ovarian cancer cells expressing ovarian tumor cell-specific antigens, which may result in ovarian tumor cell lysis. 